\title{
POPULATION DYNAMICS, AGGLOMERATION ECONOMIES AND MUNICIPAL SIZE: A LONG-TERM ANALYSIS
}

\author{
Maria Teresa CIOMMI ${ }^{1}$, Ilaria ZAMBON ${ }^{2}$, Luca SALVATI ${ }^{3,4}$ \\ ${ }^{1}$ Università Politecnica delle Marche, Ancona, Italy; ${ }^{2}$ Tuscia University, Viterbo, Italy; \\ ${ }^{3}$ Consiglio per la Ricerca in agricoltura e l'analisi dell'Economia Agraria (CREA), \\ Arezzo, Italy; ${ }^{4}$ University of Rome 'La Sapienza', Rome, Italy
}

\begin{abstract}
Under the hypothesis that modifications in municipal boundaries and creation (or suppression) of new administrative units reflect a progressive adjustment toward a more balanced distribution of population over space, the present study investigates the long-term relationship (1928-2012) between urban expansion, population dynamics and municipal area in a growing metropolitan region (Athens, Greece). In expanding regions, municipal size is a key variable outlining the amount and spatial concentration of services and infrastructures, resulting to be functionally related to population density, agglomeration factors, land availability to building and characteristic socioeconomic profiles of local communities. A statistical analysis of the relationship between population density and municipal area provides basic knowledge to policy and planning adjustments toward a more balanced spatial distribution of population and land among the local government units. Descriptive statistics, mapping, correlation analysis and linear regressions were used to assess the evolution of such relationship over a sufficiently long time period. The average municipal area in Athens decreased moderately over time, with a slight increase in spatial heterogeneity. Conversely, the average population density per municipality increased more rapidly, with a considerable reduction in spatial heterogeneity. The observed goodness-of-fit of the linear relationship between population density and municipal area increased significantly over time. The empirical results of our study indicate that municipal size has progressively adjusted to population density across metropolitan areas, determining a more balanced spatial distribution of the resident population, which was consolidated by the recent administrative reform of the local authorities in Greece (the so called 'Kallikratis' law). Such conditions represent a base for the informed analysis of the spatial structure of local administrative units and they contribute to the debate on the optimal size of municipalities and other administrative districts with relevant impact on both urban and metropolitan scales of governance.
\end{abstract}

Key Words: administrative domain, local development, urban growth, population density, Europe.

\section{Introduction}

Diseconomies of scale associated with larger governments requiring proportionally more administration are a particularly relevant issue in political science under fragmented territories and increasing competitiveness among local contexts (Dollery and Crase 2004, Schneider and Woodcock 2008, Andrews and Boyne 2009, Lassen and Serritzlew 2011, Tavares and Rodrigues 2015, Dhimitri 2018). With optimal jurisdiction size being a cornerstone in government design, a long-established tradition in political thought argues that democracy and governance efficiency thrive in smaller administrative units. In the last decades, municipal amalgamation has accounted for a substantial reduction in the number of councils in several countries worldwide (e.g. Australia: Dollery and Crase 2004; Switzerland: Steiner 2003; Canada: Keil and Boudreau 2005; but see also Allan 2003). Theories supporting programs of municipal consolidation argue that important economic benefits will flow from fewer and larger 
municipal councils. Based on the Australian experience in the 1990s, where amalgamation programs resulted in an evident decrease in the number of local administrative units, Byrnes and Dollery (2002) evaluated the validity of the assumption that larger municipalities would exhibit greater economic efficiencies. The literature review and empirical results from that study specified that this argument did not derive from an effective and solid empirical base. In other welfare systems, such as those adopted in northern European countries, unique systems of highly decentralized municipalities were historically promoted and maintained over time (UNHABITAT 2009). However, a discussion about merging municipalities has more recently emerged, e.g. in Denmark (Larsen 2002). While, non-electoral participation resulted to be higher in small municipalities, municipal size seems to be neutral in term of citizens' interest in (and knowledge of) local politics. This evidence shed further light on the classical framework of the dichotomy between capacity and proximity, linking empirical findings to more general considerations about administrative effectiveness versus democracy and citizens' participation to public choice. Lassen and Serritzlew (2011: 238) found different results from a quasiexperiment based on a large-scale municipal reform in Denmark, that allowed estimating a causal effect of administrative unit's size on internal political efficacy: "Jurisdiction size has a causal and sizeable detrimental effect on citizens' internal political efficacy". In other words, as suggested by Rose (2002: 829), the effect of size "is not merely a by-product of the compositional characteristics of the individual living in different sized municipalities". However, while it is reasonable to expect size to be relevant, the nature of the relationship may vary from one form of participation to another. In Norway, the central government has recently designed a framework to consolidate municipalities based on a voluntary program. Based on this context, Sørensen (2006) tested if political transaction costs will hinder associations, analysing some efficiency and cost proposition built on spatio-temporal data for Norwegian local authorities (Holzer et al. 2009). Reforms, especially those affecting a partial ensemble of municipalities in a region, often result in exogenous - and substantial - changes in municipal population size with uncertain impact on governance efficiency (Bel and Warner 2015).

Growing scepticism in policy circles over the efficacy of municipal consolidation as a suitable method of enhancing the operational efficiency of local councils was reported, e.g. for Australia (Dollery et al. 2007). Apart from large amalgamation programs, a range of promising alternative options was proposed "that may be able to effectively combine more efficient service delivery with vibrant local democracy" (Dollery and Johnson 2005: 73). Concerning local democracy, Keil and Boudreau (2005) discussed the establishment of more moderately liberal and social democratic administrations in some regions of Canada during the 1990s, highlighting the role of social movement demands in the revision of municipal government mechanisms. In this line of thinking, Steiner (2003: 551) found that "reform-friendly authorities, intensive social contacts among the inhabitants of the municipalities, a favourable topographic location and the policies of the superordinate government level promote enthusiasm for reforms".

By estimating the cost of providing local government services, Carey et al. (1996) introduced the notion of the 'optimal' size of administrative units, e.g. municipalities. Based on empirical models, the optimal number of administrative districts for a fixed population size in each region was identified under the assumption that the geographic aggregation of municipalities into larger and denser municipal districts will reduce the costs of public services. However, although policymakers believe that larger municipalities exhibit greater efficiency, evidences are mixed about the relationship between population density and municipal efficiency (Holzer et al. 2009). While larger municipalities with a population over 250000 are clearly less efficient, there is also little correlation between size and efficiency for municipalities with populations between 25000 and 250000 people; moreover, while the literature suggests that smaller municipalities are less efficient - outlining important deviations from this general pattern at the same time - small municipalities are demonstrated to be largely efficient in specialized services (Dhimitri 2018).

When evaluating the impact of jurisdiction size on various 'optimal' socioeconomic criteria, 
ambiguous results emerged due to several reasons, including sorting effects, data endogeneity and the lack of dedicated experiments simulating the impact of policy reforms. Moreover, by contributing to the broader issue of 'optimal city size' (Singell 1974), Capello and Camagni (2000) discussed on the notion of administrative local units' optimal size, concentrating to the concept of the 'efficient size' of a municipality or a city, based on the functional characteristics of the given spatial unit and on its spatial organization within the urban system. In this sense, processes of transformation in regional economic structures with intense population mobility (e.g. within metropolitan regions), and possibly reflected in multiple, subsequent reforms of local authorities (increasing or reducing the number and size of municipalities), may represent specific conditions under which to indirectly evaluate the controversial question of economies of scale in the local government. In a framework of widespread expansion of both state and regional planning programs, Carruthers and Ulfarsson (2002) examined the relationship between governmental fragmentation and urban development, outlining the emergent need to promote jurisdictional cooperation and regulatory consistency across metropolitan regions.

The present study contributes to this deserving issue by investigating the multiple relationships between urban expansion, agglomeration factors, population density and municipal size in a European metropolitan region - Athens, Greece - rapidly expanding between 1928 and 2012. The transformations in municipal boundaries with the creation (or suppression) of new administrative units were hypothesized to reflect a progressive adjustment toward a more balanced distribution of population over space (Salvati et al. 2013). Since municipal size is a relevant variable reflecting the amount of services and infrastructures - being functionally related with both population concentration and land availability to building in expanding metropolitan regions (Carruthers and Ulfarsson 2002, Salvati and Gargiulo Morelli 2014, Pili et al. 2017, Cecchini et al. 2018, Duvernoy et al. 2018, Wolff et al. 2018) - a quantitative analysis of the relationship between population density and municipal area is supposed to provide basic knowledge for the identification of the local administrative units' optimal size (Dhimitri 2018).

\section{Methodology}

Study area

The Athens Metropolitan Region extends nearly $3000 \mathrm{~km}^{2}$ in the administrative region of Attica in Greece, coinciding with the functional boundaries of the 'Urban Atlas' region of Athens, the capital of Greek Republic. All mainland municipalities, including those belonging to Salamina island, are considered in the study area. While the regional territory mostly consists of mountains bordering the flat area around Athens' inner city, three coastal plains (Messoghia, Marathona, Thriasio) concentrated population commuting to the urban area of Athens-Piraeus (Salvati and Serra 2016). Our analysis covers a time frame of more than 80 years between 1928 and 2012, including sequential expansion waves of Athens, fuelled by increasing population flows from Asia Minor after the 1921 War, rural-urban migration in the aftermath of World War II, natural increase driven by growing fertility and declining mortality patterns typical of the 1960s and the 1970s, as well as increasing migration flows (both internal and international) afterwards (Couch et al. 2007).

In this study, we used Greek municipalities as basic territorial entities with a degree of administrative autonomy and dedicated to the interests of local populations; the capital city (Athens) is governed by a specific municipality. In urban and regional studies, municipalities are frequently used as basic units of analysis. In addition to municipalities, there is also the entity of metropolitan areas, which bring together many municipalities. As the metropolitan area of Athens, a metropolitan area defines an agglomeration (or conurbation) which, for its various services and activities, depends on the central city (in this case, Athens) and it is characterized by the integration of its functions and the intensity of its relations regarding economic activities, services, cultural and territorial characteristics. Additional elements supporting a metropolitan 
area are the presence of a transport network connecting the different urban areas and the presence of intense social interactions within the area.

In this paper, we analysed two quasi-experiments in terms of municipal restructuring (Hlepas 2010, Ladi 2014, Featherstone 2015): (i) the progressive increase in the number of municipal units under the same general spatial framework (based on the traditional spatial asset of municipalities in Greece, consolidated with the more recent 'Kapodistrias' organization structure; this structure was adapted to manage intense population growth and massive urban expansion into rural areas (between 1928 and 2011) and it resulted in a partition of the study region into more than 100 administrative domains (Fig. 1); and (ii) a more recent reform of local government units (2011), the so called 'Kallikratis' law approved by the Greek parliament and reducing the number of municipalities to nearly 60 in the study area (Hlepas and Getimis 2011, Colantoni et al. 2016a, 2016b, Rontos et al. 2016). Fig. 2 illustrates the temporal period with maximum urban concentration for each municipality, based on the vertical profile of buildings. Descriptive statistics, correlation analysis and linear regressions were used to evaluate such relationships over time, informing on the political and planning adjustments to a more balanced spatial distribution of population and land among the local government units.

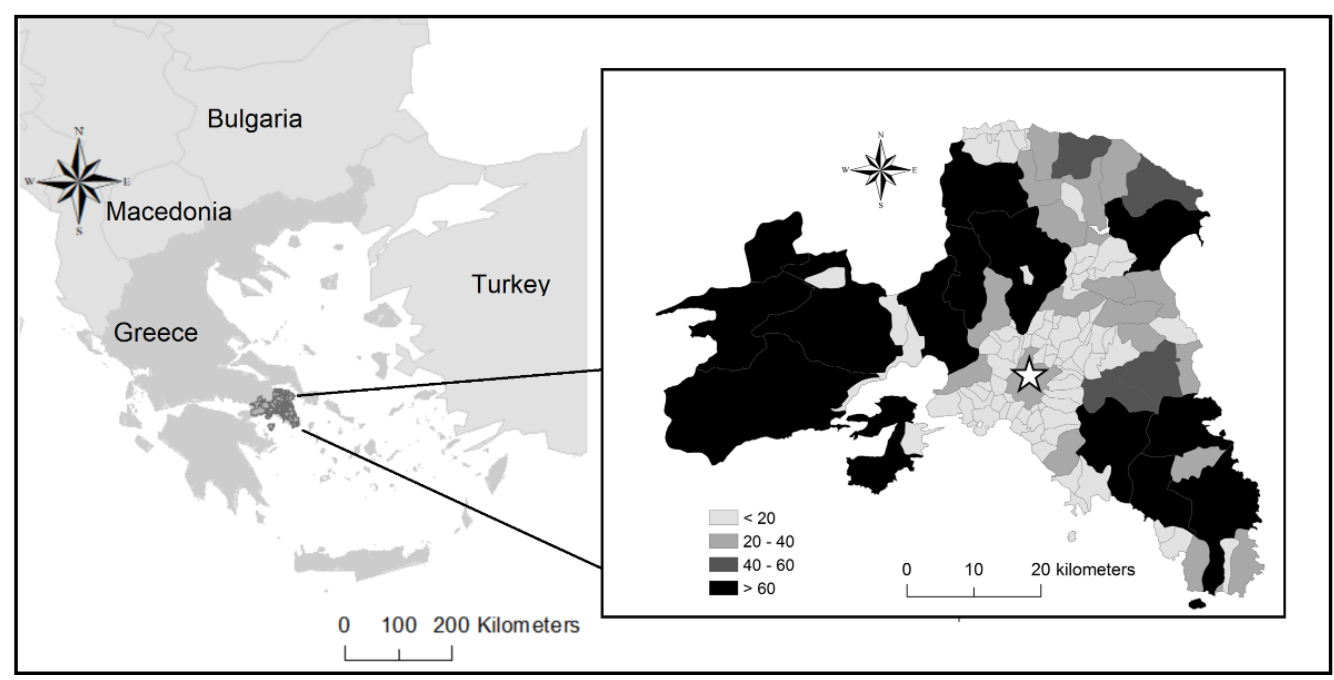

Fig. 1 - Boundaries and size $\left(\mathrm{km}^{2}\right)$ of municipalities belonging to Athens' metropolitan region in 2011

Source: traditional spatial organization of local authorities (the star indicates the downtown of Athens)

\section{Indicators}

Municipal area $\left(\mathrm{km}^{2}\right)$ and population size (total resident inhabitants) were derived from the National Population Census held by the National Statistical Service of Greece (NSSG, now ELSTAT) approximately every 10 years (1928, 1940, 1951, 1961, 1971, 1981, 1991, 2001 and 2011). The population density per municipality was calculated based on these data. A vector map of municipalities provided by ELSTAT was used to illustrate the spatial distribution of the studied variables. The relationship between population density and municipal size was illustrated in Fig. 3; the scatterplot evidenced a logarithmic form that distinguishes urban municipalities (small size and high population density) from rural municipalities (large size and low population density). 


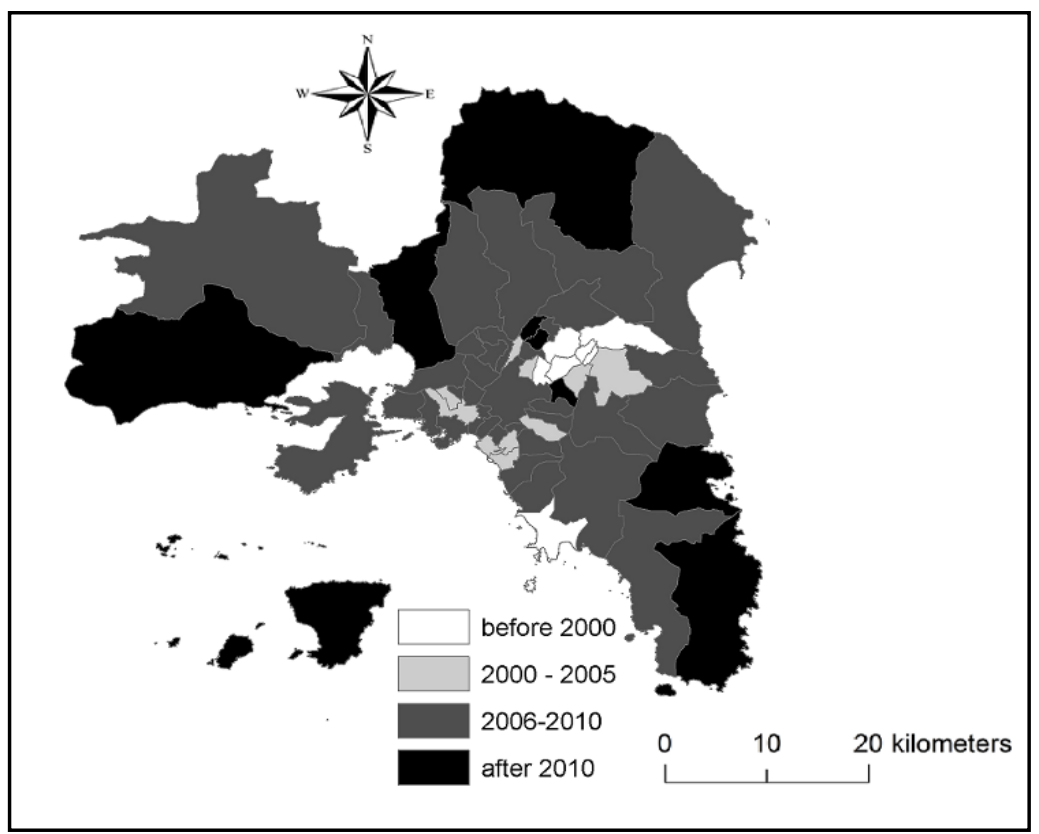

Fig. 2 - Boundaries of municipalities belonging to Athens' metropolitan region in 2012 Source: 'Kallikratis' reform of local authorities in Greece, illustrating the temporal period with maximum urban concentration based on the vertical profile of buildings
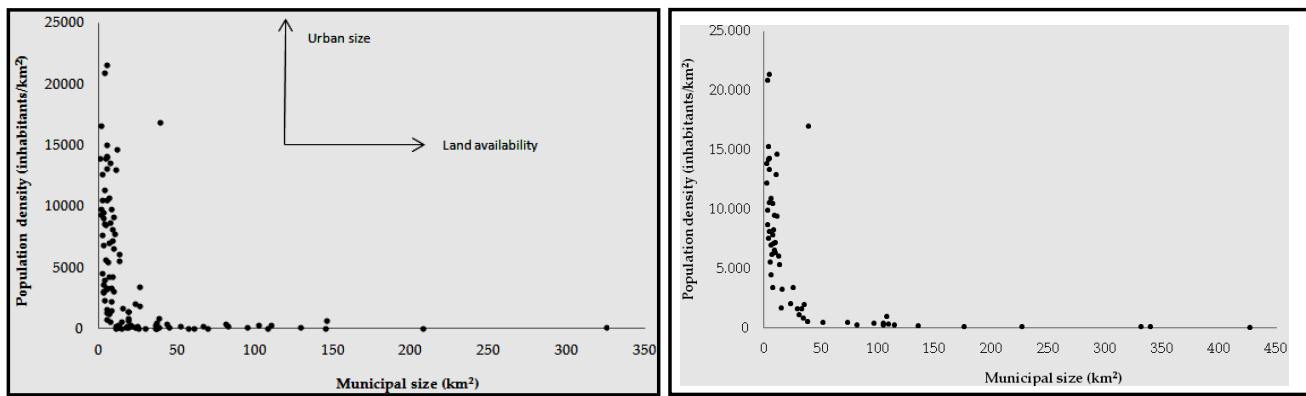

Fig. 3 - Scatterplots illustrating the relationship between population density and municipal size (left: 'Kapodistrias' spatial organization; right: 'Kallikratis' reform of local authorities) in the study area (2011 population data), evidencing agglomeration factors (urban size) and rural dimension (land availability)

\section{Statistical analysis}

Under the hypothesis that municipal size is negatively correlated with population density, the present study proposes a comprehensive approach to evaluate the implications of this relationship in terms of optimal municipal size, using time series population data covering a sufficiently long temporal period (60 years), from 1951 to 2011. Considering the logarithmic relation between population density and municipal size illustrated above, a log-log correlation 
analysis between population density and municipal size in the study area was run to assess changes in correlation with regime over time. Three correlation coefficients, using both parametric (Pearson) and non-parametric (Spearman and Kendall) techniques, were tested with the final objective to identify both linear and non-linear relationships between the two variables. The similar values in the three correlation coefficients indicate a linear relationship between variables. Based on these findings, a linear regression model was run using log (municipal size) as dependent variable and log (population density) as independent variable separately for each year of investigation (from 1928 to 2012). Slope coefficients and intercepts, together with the respective adjusted- $R^{2}$, were analysed as the model's output. The ratio between slope and intercept was computed for each time point with the aim to evaluate the changes over time in the spatial structure of the relationship between the two variables. For the two selected years (1928 and 2011), based on the traditional spatial asset of local units, different polynomial models (from grade 2 to 6 ) regressing log (municipal size) to log (population density) were run with the final objective to demonstrate that a linear form is the best descriptor of the relationship mentioned above. Percent increases in the $R^{2}$ with rising equation grade (e.g. from grade 1 - linear form - to grade 2 - square relation) were computed separately for models referring to 1951 and 2011.

\section{Results}

The number of municipalities increased slightly in the Athens' metropolitan region during the study period (Table 1). Based on the traditional spatial asset of local governance units, the median municipal size decreased moderately from $13 \mathrm{~km}^{2}$ to nearly $9 \mathrm{~km}^{2}$, with an increasing spatial variability. The median population stock per municipality increased considerably because of inherent processes of urban growth. Consequently, the median density of resident population increased over time with an evident decrease in spatial variability. The 'Kallikratis' spatial asset of local authorities resulted in a consolidation of previous trends in municipal area and population distribution, with larger municipal size $\left(11.2 \mathrm{~km}^{2}\right)$ and resident population (median per municipality) three-time higher than the precedent spatial asset.

Table 1

Municipal size, absolute population and population density in the Athens' metropolitan region, by year (1928-2012)

\begin{tabular}{|c|c|c|c|c|c|c|c|}
\hline \multirow{2}{*}{ Year } & \multirow{2}{*}{$\frac{\text { No }}{\text { municip. }}$} & \multicolumn{2}{|c|}{$\begin{array}{c}\text { Municipal size } \\
\left(\mathrm{km}^{2}\right)\end{array}$} & \multicolumn{2}{|c|}{$\begin{array}{l}\text { Absolute population } \\
\text { (inhabitants) }\end{array}$} & \multicolumn{2}{|c|}{$\begin{array}{l}\text { Population density } \\
\left(\text { inh. } / \mathrm{km}^{2}\right)\end{array}$} \\
\hline & & Median & $\mathrm{CV}$ & Median & $\mathrm{CV}$ & Median & $\mathrm{CV}$ \\
\hline 1928 & 96 & 13.4 & 1.5 & 1,313 & 4.5 & 57 & 2.9 \\
\hline 1940 & 103 & 12.0 & 1.6 & 2,231 & 4.1 & 140 & 2.2 \\
\hline 1951 & 105 & 10.7 & 1.6 & 3,305 & 4.0 & 214 & 2.0 \\
\hline 1961 & 109 & 10.5 & 1.6 & 5,503 & 3.4 & 331 & 1.7 \\
\hline 1971 & 112 & 9.8 & 1.6 & 7,812 & 3.4 & 544 & 1.5 \\
\hline 1981 & 115 & 9.5 & 1.6 & 10,100 & 2.9 & 637 & 1.4 \\
\hline 1991 & 115 & 9.5 & 1.6 & 12,023 & 2.5 & 1235 & 1.3 \\
\hline 2001 & 115 & 9.5 & 1.6 & 13,921 & 2.3 & 1401 & 1.3 \\
\hline 2011 & 115 & 9.5 & 1.6 & 16,002 & 2.0 & 1717 & 1.2 \\
\hline $2012^{*}$ & 59 & 11.2 & 1.7 & 46,897 & 1.3 & 6072 & 0.9 \\
\hline
\end{tabular}

Statistical figures include median and CV, Coefficient of variation;

*indicates a time point referring to the 'Kallikratis' spatial asset. 
The empirical relationship between log (municipal size) and log (population density) in the Athens' metropolitan region was illustrated in Fig. 4 for the first and the last points in time considered in this study, using the same spatial asset ('Kapodistrias' municipalities). The relation was linear at the end of the study period (2011) and more scattered at the beginning of the study period (1951).
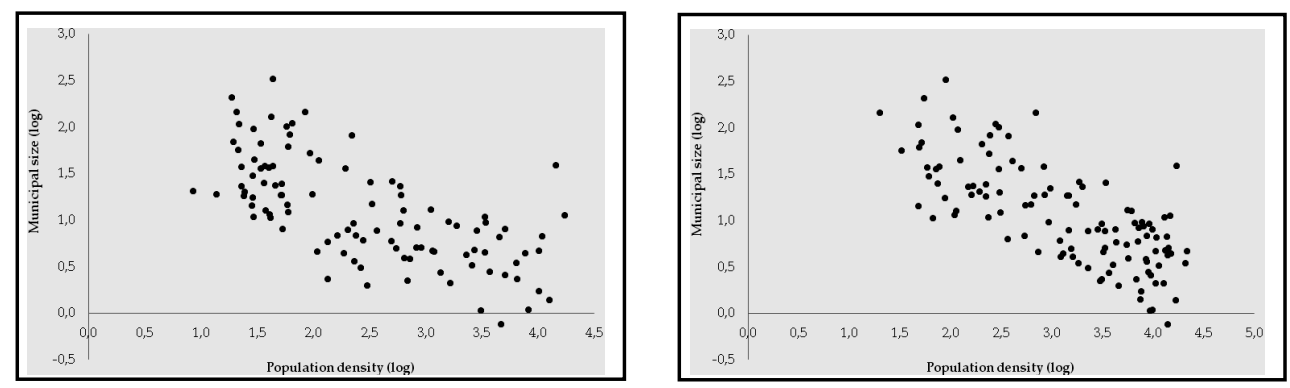

Fig. 4 - A log-log scatterplot illustrating the relationship between municipal area ('Kapodistrias' spatial asset) and population density, in 1951 (left) and 2011 (right), in the study area

Table 2 reports the main results of a correlation analysis between log (municipal area) and log (population density) or log (population stock) based on three (parametric and non-parametric) correlation coefficients. As far as population stock is concerned, all tested correlations were statistically not significant $(p>0.05)$ for all investigated years and correlation techniques, possibly indicating a substantial independence between population size and municipal size (the correlation coefficients are available on request). Concerning the population density, all coefficients were characterized by a comparable pattern, increasing over time to a peak observed at the end of the study period. All correlation coefficients were negative and significant at $p<0.001$.

Regressions indicate an increasing goodness-of-fit of the linear model predicting municipal size on the base of population density (Table 3 ). Adjusted- $R^{2}$ increased over time from 0.25 to 0.87 ; however, this increase followed a U-shaped pattern with the lowest value observed for 1971, in parallel with the highest urban concentration in the study area (Salvati et al. 2016). Slope-tointercept ratio indicated a substantial break-point in the investigated time series during the 1970s, corroborating the results presented above. The regression results referring to the new spatial asset ('Kallikratis') were in line with the earlier evidence, indicating a substantial consolidation of previous trends in both slope and intercept. For instance, the rapid (negative) increase of slope for 'Kallikratis' asset is in line with the less intense, long-term increases observed since 1981 and paralleling the de-centralized metropolitan growth typical of the study area.

Table 4 reports the percent improvement in goodness-of-fit (based on the adjusted $\mathrm{R}^{2}$ metric) of models predicting municipal size from population density that use polynomial functional forms of variable grade from 2 to 6 . Percent improvement in the $\mathrm{R}^{2}$ goodness-of-fit using different polynomial models was calculated separately for the two selected years (1951 and 2011) based on the same spatial asset of local municipalities. This time period was considered rather homogeneous in term of mechanisms of urban growth and spatial structure. Although modest increases were observed for both years - thus validating a linear form between municipal size and population density in the study area - the $\mathrm{R}^{2}$ percent improvement was systematically higher for all polynomial grades when applied to 1951 data than for 2011 data. 
This evidence is in line with the descriptive analysis, outlining a less scattered distribution of observations in 2011 than in 1951.

Table 2

Correlation analysis (left) between municipal area (log) and absolute population (log) or population density (log) using both parametric (Pearson) and non-parametric (Spearman and Kendall) coefficients, by year (1928-2011)

\begin{tabular}{|l|l|c|c|c|}
\hline \multirow{2}{*}{ Year } & \multicolumn{3}{|c|}{ Population density } \\
\cline { 2 - 4 } & & Pearson & Spearman & Kendall \\
\hline 1928 & $-0.59^{*}$ & $-0.54^{*}$ & $-0.37^{*}$ \\
\hline 1940 & & $-0.66^{*}$ & $-0.66^{*}$ & $-0.46^{*}$ \\
\hline 1951 & & $-0.69^{*}$ & $-0.71^{*}$ & $-0.50^{*}$ \\
\hline 1961 & & $-0.73^{*}$ & $-0.69^{*}$ & $-0.49^{*}$ \\
\hline 1971 & & $-0.73^{*}$ & $-0.69^{*}$ & $-0.48^{*}$ \\
\hline 1981 & & $-0.75^{*}$ & $-0.69^{*}$ & $-0.48^{*}$ \\
\hline 1991 & & $-0.75^{*}$ & $-0.73^{*}$ & $-0.51^{*}$ \\
\hline 2001 & & $-0.77^{*}$ & $-0.74^{*}$ & $-0.53^{*}$ \\
\hline 2011 & & $-0.77^{*}$ & $-0.74^{*}$ & $-0.52^{*}$ \\
\hline $2012^{* *}$ & $-0.94^{*}$ & $-0.85^{*}$ & $-0.71^{*}$ \\
\hline
\end{tabular}

*significant at $p<0.05$; *indicates a time point referring to the 'Kallikratis' spatial asset

Table 3

Results of linear regression (right) with municipal area (log) as dependent variable and population density (log) as predictor in the Athens' metropolitan region, by year (1928-2011)

\begin{tabular}{|l|c|c|c|c|c|c|c|}
\hline Year & & Intercept & Slope & Slope/Interc & Adj-R & df & Durbin-W. \\
\hline 1928 & & $1.83(0.13)$ & $-0.34(0.06)$ & -0.18 & $0.25^{*}$ & $1 ; 94$ & 1.62 \\
\hline 1940 & & $2.06(0.13)$ & $-0.41(0.05)$ & -0.20 & $0.37^{* *}$ & $1 ; 101$ & 1.63 \\
\hline 1951 & & $2.14(0.12)$ & $-0.42(0.04)$ & -0.20 & $0.46^{* *}$ & $1 ; 103$ & 1.63 \\
\hline 1961 & & $2.12(0.11)$ & $-0.40(0.04)$ & -0.19 & $0.46^{* *}$ & $1 ; 107$ & 1.57 \\
\hline 1971 & & $2.14(0.11)$ & $-0.39(0.04)$ & -0.18 & $0.47^{* *}$ & $1 ; 110$ & 1.52 \\
\hline 1981 & & $2.22(0.12)$ & $-0.40(0.04)$ & -0.18 & $0.48^{* *}$ & $1 ; 113$ & 1.50 \\
\hline 1991 & $2.42(0.12)$ & $-0.45(0.04)$ & -0.19 & $0.53^{* *}$ & $1 ; 113$ & 1.61 \\
\hline 2001 & & $2.56(0.13)$ & $-0.49(0.04)$ & -0.19 & $0.55^{* *}$ & $1 ; 113$ & 1.66 \\
\hline 2011 & & $2.60(0.13)$ & $-0.49(0.04)$ & -0.19 & $0.56^{* *}$ & $1 ; 113$ & 1.70 \\
\hline 2012 & & $3.98(0.14)$ & $-0.79(0.04)$ & -0.20 & $0.87^{* *}$ & $1 ; 57$ & 1.70 \\
\hline
\end{tabular}

Df-degrees of freedom; Durbin-W. - Durbin-Watson statistics; Intercept's and slope's errors in brackets; Significant coefficient at ${ }^{*} p<0.05$ or ${ }^{* *} p<0.001$; The italics indicates data referring to the 'Kallikratis' spatial asset

Table 4

Per cent gain in the adjusted- $R^{2}$ goodness-of-fit of the relationship between municipal area and population density with the use of polynomial equations of increasing grade following Kapodistrias spatial asset of local units (selected years: 1951 and 2011)

\begin{tabular}{|l|c|c|}
\hline Grade & 1951 & 2011 \\
\hline 2 vs 1 & 5.1 & 0.2 \\
\hline 3 vs 2 & 4.4 & 1.4 \\
\hline 4 vs 3 & 0.2 & 1.6 \\
\hline 5 vs 4 & 3.6 & 0.5 \\
\hline 6 vs 5 & 0.8 & 0.1 \\
\hline
\end{tabular}




\section{Discussion}

Based on the inherent evolution of agglomeration factors, recent spatial changes in population structures reflect distinctive urbanization processes occurring in several European large- and medium-size cities, and causing a spatial (re)balancing of activities and population deconcentration (Kasanko et al. 2006, Longhi and Musolesi 2007, Carlucci et al. 2017, CuadradoCiuraneta et al. 2017, Zambon et al. 2018). By investigating the latent relationship between population density and municipal area in a European metropolitan region expanding in the last 60 years, our study has contributed to a multi-criteria assessment of optimal municipal size (Serra et al. 2014, Zitti et al. 2015, Salvati et al. 2017, Pili et al. 2017). Under the assumption that changes in municipal boundaries (with creation/suppression of new administrative units) are associated with progressive adjustments toward a more balanced distribution of population over space (Carruthers and Ulfarsson 2002), the relationship between municipal size and population density was considered a proxy for services' and infrastructures' concentration (Vallebona et al. 2016), since this relationship is functionally related with both population concentration and land availability to building (e.g. Byrnes and Dollery 2002, Holzer et al. 2009, Larsen and Hertwich 2010).

The empirical results presented in this paper suggest that municipal size has progressively adjusted to population density, creating a more balanced spatial asset in the most recent decades (Rees 1992). Urban concentration typical of the 1970s in the study area was likely the condition that contributed the most to spatial variability and heterogeneity in the relationship between municipal size and population density (e.g. Salvati et al. 2013), possibly influencing the estimation of an optimal size for administrative local units, based on ex-ante criteria (Salvati et al. 2015). Transformations in municipal boundaries with the creation (or suppression) of new administrative units effectively reflect a progressive change toward a more balanced population distribution over space (Salvati and Zitti 2005). Spatially-balanced socioeconomic conditions seem to be a reasonable pre-requisite to an effective identification of optimal municipal size according to place-specific criteria (Salvati and Carlucci 2016). Municipal size decreased moderately over time with a slight increase in spatial heterogeneity; conversely, the average population density per municipality increased more rapidly with an evident reduction in spatial heterogeneity. The linearity and significance of the relationship between municipal size and population density both increased over time, reaching the highest values in 2011 (under the same spatial structure consolidated with the 'Kapodistrias' municipal asset) and reinforcing in the following years, under the renewed 'Kallikratis' spatial asset of local government units.

Taken together, these conditions represent a base for the informed analysis of the spatial structure of local administrative units and a pre-requisite for the identification of optimal municipal size (Dhimitri 2018). In line with earlier studies (Salvati et al. 2016, Bharath et al. 2017, Prasanth Warrier and Praseeja 2017), this work demonstrates how a quantitative analysis of the relationship between population density and municipal area, based on descriptive statistics, multiple correlation coefficients and regression models, provides basic knowledge for the identification of optimal municipal size, and it allows assessing the political and planning targets that involve a more balanced spatial distribution of population and land among local government units (Rose 2002, Zambon et al. 2017). Based on these empirical findings, the optimal municipal size should be regarded as a non-linear and evolving notion based on the intimate dynamics of the regional system under investigation. The use of dynamic criteria to determine the optimal municipal size over time and space is relevant in rapidlyexpanding metropolitan regions and, more generally, in economically-dynamic contexts with high residential mobility and re-location of activities into wider areas.

The policy implementations of the exploratory analysis developed in this work are grounded in the mutual interaction between population distribution, urban concentration and municipal size, with a specific focus on expanding metropolitan regions. The analysis proposed here was 
based on homogeneous indicators derived from official statistics over a long-time interval and on simplified statistical techniques, whose results provide a knowledge base for improved policies of local development and the sustainable planning of metropolitan districts in the light of the 'optimal municipal size' theory. The empirical evidence of this study indicates that a stronger integration between demographic, economic and political indicators is required to achieve a more comprehensive picture of local administrative structures based on an enhanced knowledge of the socioeconomic context differing among local communities. Further investigation is required to shed light on the intimate relationship between the changing spatial asset of local governance and the underlying socioeconomic transformations in progressively more complex and fragmented metropolitan systems.

\section{Conclusions}

Both changes in municipal boundaries and the creation (or suppression) of new administrative units reflect a progressive alteration toward a more balanced population distribution over space. Municipal size is a key variable delineating the amount and spatial concentration of services and infrastructures, being functionally related with population density, agglomeration factors, land availability to building and a characteristic profile of local communities in expanding metropolitan regions. The long-term relationship (1928-2012) between urban expansion, population dynamics and municipal area in a growing metropolitan region (Athens, Greece) was explored through a simplified statistical analysis of the relationship between population density and municipal area, providing basic knowledge to policy and planning adjustments toward a more balanced spatial distribution of population and land among the local government units. Descriptive statistics, mapping, correlation analysis and linear regressions were used to assess the evolution of such relationships over a sufficiently long time period and they proved to be a comprehensive analytical framework for the investigation of spatiallyexplicit issues associated with municipal size, population density and urban expansion. The average municipal area in Athens decreased moderately over time with a slight increase in spatial heterogeneity; conversely, the average population density per municipality increased more rapidly with a marked reduction in spatial heterogeneity. The results specify that municipal size has increasingly adjusted to population density across metropolitan regions, determining a more balanced spatial distribution of the resident population. Such conditions provide an improved knowledge base for a spatially-explicit analysis of local administrative units and they justify an enriched, evidence-based discussion on the optimal size of municipalities and administrative urban districts. Further studies should develop a comparative analysis of municipal size under the changing socioeconomic conditions in different metropolitan regions of advanced countries, with the aim to corroborate the hypothesis formulated at the base of this work and to generalize the empirical findings of our study to vastly different background contexts.

\section{References}

ALLAN P. (2003), Why Smaller Councils Make Sense, Australian Journal of Public Administration 62 (3), 74-81.

ANDREWS R., BOYNE G. A. (2009), Size, structure and administrative overheads: An empirical analysis of English local authorities, Urban Studies 46 (4), 739-759.

BHARATH H. A., CHANDAN M. C., VINAY S., RAMACHANDRA T. V. (2017), Intra and Inter Spatio-Temporal Patterns of Urbanisation in Indian Megacities, International Journal of Imaging and Robotics 17 (2), 68-86.

BEL G., WARNER M. E. (2015), Inter-municipal cooperation and costs: Expectations and evidence, Public Administration 93 (1), 52-67.

BYRNES J., DOLLERY B. (2002), Do Economies of Scale Exist in Australian Local Government? A Review of the Research Evidence, Urban Policy and Research 20 (4), 391- 
Population Dynamics, Agglomeration Economies and Municipal Size: a Long-Term Analysis

414.

CAPELLO R., CAMAGNI R. (2000), Beyond Optimal City Size: An Evaluation of Alternative Urban Growth Patterns, Urban Studies 37 (9), 1479-1496.

CAREY M., SRINIVASAN A., STRAUSS R. P. (1996), Optimal Consolidation of Municipalities: An Analysis of Alternative Designs, Socio-Economic Planning Sciences 30 (2), 103-119.

CARLUCCI M., GRIGORIADIS E., RONTOS K., SALVATI L. (2017), Revisiting a Hegemonic Concept: Long-term 'Mediterranean Urbanization' in between city re-polarization and metropolitan decline, Applied Spatial Analysis and Policy 10 (3), 347-362.

CARRUTHERS J. I., ULFARSSON G. F. (2002), Fragmentation and Sprawl: Evidence from Interregional Analysis, Growth and Change 33 (3), 312-340.

CECCHINI M., ZAMBON I., PONTRANDOLFI A., TURCO R., COLANTONI A., MAVRAKIS A., SALVATI L. (2018), Urban sprawl and the 'olive' landscape: sustainable land management for 'crisis' cities, GeoJournal 84 (1), 237-255.

COLANTONI A., GRIGORIADIS E., SATERIANO A., VENANZONI G., SALVATI L. (2016a), Cities as selective land predators? A lesson on urban growth, deregulated planning and sprawl containment, Science of the Total Environment 545-546, 329-339.

COLANTONI A., GRIGORIADIS E., SATERIANO A., ZAMBON I., SALVATI L. (2016b), If the Sky Falls We Shall Catch Larks: Rethinking Land Quality and Desertification Risk into a Regional Science Framework, International Journal of Ecological Economics and Statistics 37 (3), 64-75.

COUCH C., PETSCHEL-HELD G., LEONTIDOU L. (eds.) (2007), Urban Sprawl in Europe: Landscapes, Land-use Change and Policy, Blackwell Publishing, London.

CUADRADO-CIURANETA S., DURÀ-GUIMERÀ A., SALVATI L. (2017), Not only tourism: unravelling suburbanization, second-home expansion and "rural" sprawl in Catalonia, Spain, Urban Geography 38 (1), 66-89.

DHIMITRI E. (2018), Analysis Related to Optimal Size of Municipality and Efficiency - A Literature Review, European Journal of Interdisciplinary Studies 4 (1), 131-138.

DOLLERY B., BYRNES J., CRASE L. (2007), Is Bigger Better? Local Government Amalgamation and the South Australian Rising to the Challenge Inquiry, Economic Analysis and Policy 37 (1), 1-14.

DOLLERY B., CRASE L. (2004), Is bigger local government better? An evaluation of the case for Australian municipal amalgamation programs, Urban Policy and Research 22 (3), 265-275.

DOLLERY B., JOHNSON A. (2005), Enhancing efficiency in Australian local government: An evaluation of alternative models of municipal governance, Urban Policy and Research 23 (1), 73-85

DUVERNOY I., ZAMBON I., SATERIANO A., SALVATI L. (2018), Pictures from the Other Side of the Fringe: Urban Growth and Peri-urban Agriculture in a Post-industrial City (Toulouse, France), Journal of Rural Studies 57, 25-35.

FEATHERSTONE K. (2015), External conditionality and the debt crisis: the 'Troika' and public administration reform in Greece, Journal of European Public Policy 22 (3), 295-314.

HLEPAS N.-K. (2010), Incomplete Greek Territorial Consolidation: From the First

(1998) to the Second (2008-09) Wave of Reforms, Local Government Studies 36 (2), 223-249.

HLEPAS N. K., GETIMIS P. (2011), Impacts of local government reforms in Greece: An interim assessment, Local Government Studies 37 (5), 517-532.

HOLZER M., FRY J., CHARBONNEAU E., VAN RYZIN G., WANG T., BURNASH E. (2009), Literature review and analysis related to optimal municipal size and efficiency, School of Public Affairs and Administration, Rutgers-Newark.

KASANKO M., BARREDO J. I., LAVALLE C., MCCORMICK N., DEMICHELI L., SAGRIS V., BREZGER A. (2006), Are European Cities Becoming Dispersed? A Comparative Analysis of Fifteen European Urban Areas, Landscape and Urban Planning 77 (1-2), 111-130.

KEIL R., BOUDREAU J.-A. (2005), Is there regionalism after municipal amalgamation in Toronto?, City 9 (1), 9-22. 
LADI S. (2014), Austerity politics and administrative reform: The Eurozone crisis and its impact upon Greek public administration, Comparative European Politics 12 (2), 184-208.

LARSEN C. A. (2002), Municipal size and democracy: a critical analysis of the argument of proximity based on the case of Denmark, Scandinavian Political Studies 25 (4), 317-332.

LARSEN H. N., HERTWICH E. G. (2010), Identifying important characteristics of municipal carbon footprints, Ecological Economics 70 (1), 60-66.

LASSEN D. D., SERRITZLEW S. (2011), Jurisdiction size and local democracy: Evidence on internal political efficacy from large-scale municipal reform, American Political Science Review 105 (2), 238-258.

LONGHI C., MUSOLESI A. (2007), European cities in the process of economic integration: towards structural convergence, Annals of Regional Science 41 (2), 333-351.

PILI S., GRIGORIADIS E., CARLUCCI M., CLEMENTE M., SALVATI L. (2017), Towards sustainable growth? A multi-criteria assessment of (changing) urban forms, Ecological Indicators 76, 71-80.

PRASANTH WARRIER C. B., PRASEEJA C. B. (2017), A Markov Chain Model for the Demographic Study: A Case Study on Urbanization, International Journal of Mathematics and Computation 28 (4), 21-30.

REES W. E. (1992), Ecological footprints and appropriated carrying capacity: what urban economics leaves out, Environment and Urbanization 4 (2), 121-130.

RONTOS K., GRIGORIADIS E., SATERIANO A., SYRMALI M., VAVOURAS I., SALVATI L. (2016), Lost in Protest, Found in Segregation: Divided Cities in the Light of the 2015 "OXI" Referendum in Greece, City, Culture and Society 7 (3), 139-148.

ROSE L. E. (2002), Municipal size and local nonelectoral participation: findings from Denmark, the Netherlands, and Norway, Environment and Planning C: Politics and Space 20 (6), 829-851.

SALVATI L., ZITTI M. (2005), Land degradation in the Mediterranean Basin: Linking biophysical and economic factors into an ecological perspective, Biota 6 (1-2), 67-77.

SALVATI L., CARLUCCI M. (2016), Patterns of sprawl: The socioeconomic and territorial profile of dispersed urban areas in Italy, Regional Studies 50 (8), 1346-1359.

SALVATI L., GARGIULO MORELLI V. (2014), Unveiling Urban Sprawl in the Mediterranean Region: Towards a Latent Urban Transformation?, International Journal of Urban and Regional Research 38 (6), 1935-1953.

SALVATI L., SERRA P. (2016), Estimating rapidity of change in complex urban systems: a multidimensional, local-scale approach, Geographical Analysis 48 (2), 132-156.

SALVATI L., GARGIULO MORELLI V., RONTOS K., SABBI A. (2013), Latent Exurban Development: City Expansion Along the Rural-To-Urban Gradient in Growing and Declining Regions of Southern Europe, Urban Geography 34 (3), 376-394.

SALVATI L., MAVRAKIS A., SERRA P., CARLUCCI M. (2015), Lost in translation, found in entropy: An exploratory data analysis of latent growth factors in a Mediterranean city (1960-2010), Applied Geography 60, 107-119.

SALVATI L., ZITTI M., PERINI L. (2016), Fifty years on: long-term patterns of land sensitivity to desertification in Italy, Land Degradation \& Development 27 (2), 97-107.

SALVATI L., TOMBOLINI I., GEMMITI R., CARLUCCI M., BAJOCCO S., PERINI L., FERRARA A., COLANTONI A. (2017), Complexity in action: Untangling latent relationships between land quality, economic structures and socio-spatial patterns in Italy, PLOS ONE 12 (6), e0177853.

SCHNEIDER A., WOODCOCK C. E. (2008), Compact, dispersed, fragmented, extensive? A comparison of urban growth in twenty-five global cities using remotely sensed data, pattern metrics and census information, Urban Studies 45 (3), 659-692.

SERRA P., VERA A., TULLA A. F., SALVATI L. (2014), Beyond urban-rural dichotomy: Exploring socioeconomic and land-use processes of change in Spain (1991-2011), Applied Geography 55, 71-81.

SINGELL L. D. (1974), Optimum City Size: Some Thoughts on Theory and Policy, Land 
Population Dynamics, Agglomeration Economies and Municipal Size: a Long-Term Analysis

Economics 50 (3), 207-212.

SØRENSEN R. J. (2006), Local Government Consolidations: The Impact of Political Transaction Costs, Public Choice 127 (1-2), 75-95.

STEINER R. (2003), The causes, spread and effects of intermunicipal cooperation and municipal mergers in Switzerland, Public Management Review 5 (4), 551-571.

TAVARES A. F., RODRIGUES M. (2015), The economic and political impacts of topdown territorial reforms: the case of sub-city governments, Local Government Studies 41 (6), 956-976.

UN-HABITAT (2009), Planning sustainable cities: global report on human settlements 2009, Earthscan, London.

VALLEBONA C., MANTINO A., BONARI E. (2016), Exploring the potential of perennial crops in reducing soil erosion: A GIS-based scenario analysis in southern Tuscany, Italy, Applied Geography 66, 119-131.

WOLFF M., HAASE D., HAASE A. (2018), Compact or spread? A quantitative spatial model of urban areas in Europe since 1990, PLOS ONE 13 (2), e0192326.

ZAMBON I., SERRA P., BENCARDINO M., CARLUCCI M., SALVATI L. (2017), Prefiguring a future city: urban growth, spatial planning and the economic local context in Catalonia, European Planning Studies 25 (10), 1797-1817.

ZAMBON I., FERRARA A., SALVIA R., MOSCONI E. M., FICI L., TURCO R., SALVATI L. (2018), Rural Districts between Urbanization and Land Abandonment: Undermining LongTerm Changes in Mediterranean Landscapes, Sustainability 10 (4), 1159.

ZITTI M., FERRARA C., PERINI L., CARLUCCI M., SALVATI L. (2015), Long-term urban growth and land use efficiency in Southern Europe: Implications for sustainable land management, Sustainability 7 (3), 3359-3385.

Initial submission: 08.05.2018

Revised submission: 24.09 .2018

Final acceptance: 22.04.2019

Correspondence: Department of Social and Economic Sciences, University of Rome 'La Sapienza', Piazzale A. Moro 5, I-00185, Rome, Italy.

Email: luca.salvati@uniroma1.it 
